\title{
Streptomyces peucetius daunorubicin biosynthesis gene, dnrF: sequence and heterologous expression
}

\author{
Silvia Filippini, ${ }^{1}$ Maria Manuela Solinas, ${ }^{2}$ Umberto Breme, ${ }^{1}$ \\ Manuela Birgit Schlüter, ${ }^{2}$ Davide Gabellini, ${ }^{2}$ Giuseppe Biamonti, ${ }^{2}$ \\ Anna Luisa Colombo' and Luisa Garofano'
}

Author for correspondence: Silvia Filippini. Tel: +39 331 583763. Fax: +39 331583755.

\footnotetext{
1 BioScience Center PHARMACIA, Via Papa Giovanni XXIII 23, 20014 Nerviano (Mi), Italy

2 Istituto di Genetica Biochimica ed Evoluzionistica del CNR Via Abbiategrasso 207, 27100 Pavia, Italy
}

\begin{abstract}
The dnrf gene, responsible for conversion of aklavinone to \&-rhodomycinone via C-11 hydroxylation, was mapped in the daunorubicin (Dnr) gene cluster of Streptomyces peucetius ATCC 29050, close to drrAB, one of the anthracyclineresistance genes. The dnrF gene was sequenced and should encode a protein of 489 amino acids with a molecular mass of $52 \mathrm{kDa}$. The deduced DnrF protein shows significant similarities with bacterial FAD- and NADPH-dependent hydroxylases either required to introduce hydroxyl groups into polycyclic aromatic polyketide antibiotics or involved in catabolism of aromatic compounds. Heterologous expression of dnrF in Streptomyces lividans TK23 and in Escherichia coli demonstrated that the gene encodes a NADPHdependent hydroxylase catalysing the hydroxylation of aklavinone to yield $\varepsilon$ rhodomycinone. The enzyme is inactive on anthracyclines glycosylated at position C-7 and its activity decreases to a different extent with other substrate modifications, indicating that DnrF has a significant substrate specificity.
\end{abstract}

Keywords: aklavinone, hydroxylase, $d n r F$ gene, anthracycline, Streptomyces peucetius

\section{INTRODUCTION}

Daunorubicin (Dnr) and especially its C-14 hydroxylated derivative doxorubicin (Dxr) are important antitumour agents used for the treatment of many different cancers (Arcamone, 1981). Unfortunately, besides their antineoplastic activity, they have long-term undesirable effects such as cardiotoxicity (Myers et al., 1988). For this reason, studies are being done to develop new Dnr derivatives or new anthracyclines showing an increased antitumour spectrum and, at the same time, reduced cardiotoxicity (Cassinelli et al., 1978; Crespi-Perellino et al., 1982; White \& Stroshane, 1984).

New possibilities for structural changes, resulting from recent progress in the molecular genetics of Streptomyces, have opened a promising line in the development of hybrid antibiotics (Floss \& Strohl, 1991; Hopwood et al., 1985b; Hutchinson, 1992; Strohl et al., 1989). This approach requires the understanding of the anthracycline

Abbreviations : Dnr, daunorubicin ; Dxr, doxorubicin; GST, glutathione Stransferase.

The GenBank accession number of the sequence reported in this paper is U18082. biosynthetic pathway as well as the function of the single genes and enzymes involved.

Stutzman-Engwall \& Hutchinson (1989) and Otten et al. (1990) have cloned, in a series of cosmids, the entire Dnr biosynthesis gene cluster of Streptomyces peucetius ATCC 29050. Single genes of the cluster have been isolated recently, sequenced and expressed in heterologous systems to enable partial characterization of Dnr biosynthesis enzymes (Madduri et al., 1993).

Previously we reported the isolation of a Dxr-Dnr resistance gene contained in a $5.7 \mathrm{~kb}$ fragment (ric1) from S. peucetius subsp. caesius mutant 7600 derived from ATCC 27952 (Colombo et al., 1992). ric1 belongs to the Dnr cluster described by Stutzman-Engwall \& Hutchinson (1989) and the identified resistance gene corresponds to the $\operatorname{dr} A B$ gene (Guilfoile \& Hutchinson, 1991). We also presented preliminary evidence that in the same fragment, close to $\operatorname{drr} A B$, is a gene responsible for conversion of aklavinone to $\varepsilon$-rhodomycinone via hydroxylation at $\mathrm{C}$ 11. This finding is consistent with the observation, made by Guilfoile \& Hutchinson (1991), that, in S. peucetius ATCC 29050 , a spacer of $233 \mathrm{nt}$ separates the $\operatorname{drr} A B$ gene from an open reading frame (ORF) transcribed in the 
opposite direction. The ORF was only partially sequenced but comparison of the deduced first 79 amino acids revealed a significant similarity with FAD- and NADPHdependent bacterial hydroxylases (Blanco et al., 1993).

In this paper we report the sequence of the $S$. peucetius A TCC 29050 gene for the aklavinone C-11 hydroxylase $(d n r F)$ and its heterologous expression in Escherichia coli and Streptomyces lividans.

\section{METHODS}

Bacterial strains and plasmids. The strains Streptomyces lividans TK23 (obtained from D. A. Hopwood, John Innes Institute, Norwich, United Kingdom) and Streptomyces peucetius 29050 (Grein et al., 1963), 7600, 7800 and 9700 (Colombo et al., 1992) and the plasmids pWHM3 (Vara et al., 1989), pWHM603 (Guilfoile \& Hutchinson, 1991) and ric1 (Colombo et al., 1992) are described elsewhere. The ermE* promoter (Gramajo et al., 1991) was isolated from $\mathrm{pIJ} 4070$ kindly provided by M. J. Bibb (unpublished results). pUC19, M13mp18 and M13mp19 were purchased from New England Biolabs. pT7-7 was from USB and pGEX-2T was from Pharmacia Biotech. Plasmid pGP1-2 was provided by C. R. Hutchinson. The Escherichia coli strains used were JM109 (Yanisch-Perron et al., 1985), DH5 $\alpha$ (BRL) and DH1 (Hanahan, 1983).

Plasmids pFI 15 and pLA-4 contain the $d n r F$ gene, obtained by PCR amplification as detailed later, cloned into the EcoRI site of pT7-7 and pGEX-2T vectors, respectively.

Plasmid pFI 14 contains a region of $2 \cdot 2 \mathrm{~kb}$, obtained by partial digestion of pWHM603 with BamHI, cloned into the Bam HI site of the pWHM3 vector (see Fig. 1). The $1.7 \mathrm{~kb} \mathrm{XbaI}$ fragment containing the $d n r F$ gene from $\mathrm{pFI} 15$ was cloned into the XbaI site of $\mathrm{pIJ} 4070$ downstream of the ermE* promoter, obtaining plasmid pFI 16. pFI 16 was double digested with $S a c I$ and HindIII and the $2 \mathrm{~kb}$ fragment, corresponding to the ermE*-dnrF hybrid gene, was inserted into pWHM3 digested with the same enzymes to obtain pFI 20.

Chemicals. Thiostrepton was obtained from Behring Diagnostic. Aklavinone, 10-decarbomethoxy-aklavinone, 11deoxycarminomycinone, 11-deoxydaunomycinone, 11-deoxy-4demethyladriamycinone, 11-deoxycarminomycin, 11deoxydaunomycin and 11-deoxy-4-demethyldaunomycin were prepared in the laboratories of Oncology Area Pharmacia Farmitalia-Carlo Erba. Restriction enzymes and other molecular biology materials were purchased from standard commercial sources. All other chemicals and biochemicals, unless specified, were obtained from Sigma.

DNA sequence analysis. The $1.6 \mathrm{~kb}$ and $0.6 \mathrm{~kb}$ Bam HI fragments from pWHM603 (see Fig. 1) containing the $d n r F$ gene were subcloned in pUC19, M13mp18 and M13mp19 vectors. Plasmids for sequencing reactions were prepared using Qiagen columns. Single-stranded DNA templates were isolated from E. coli JM109 cultures according to the method of Sambrook et al. (1989). The templates were sequenced by the chain-termination method with Sequenase 2.0 (USB) using $\left.{ }^{35} \mathrm{~S}\right] \mathrm{dCTP} \alpha \mathrm{S}$ following the manufacturer's instructions and $7-$ deaza-dGTP or dITP to reduce the number of sequencing artefacts. Synthetic oligonucleotide primers made by a DNA synthesizer model 391 (Applied Biosystems) were used to obtain the nucleotide sequence of both strands. FASTA and TFASTA searches were performed with the GenBank databank.

Expression of the DnrF protein in $E$. coli and the bioconversion assay. Plasmid pFI 14 was used as template for the amplification of the $d n r F$ gene. PCR was carried out with the GeneAmp DNA amplification kit (Perkin Elmer Cetus) ac- cording to the instructions of the manufacturer except for the addition of glycerol $(10 \%, \mathrm{v} / \mathrm{v}$, final concentration) and formamide $(5 \%, v / v)$. The primers used in the amplification reaction were: $5^{\prime}-d n r F$ (5' AGGAATTCAGGTG GCCTTGACGAAGCCGGATGTC $3^{\prime}$ ) containing the putative GTG translation start site (underlined) and $3^{\prime}-d n r F\left(5^{\prime}\right.$ AGGAATTCGGGACGCTCCGGTCAGCGGGCCAGC 3') $128 \mathrm{nt}$ downstream of the ORF stop codon. Both primers have an EcoRI site at their $5^{\prime}$ end (bold). Before addition of Taq polymerase and dNTPs, the reaction mixture was heated at $95{ }^{\circ} \mathrm{C}$ for $7 \mathrm{~min}$, overlaid with mineral oil and then incubated for $3 \mathrm{~min}$ at $70^{\circ} \mathrm{C}$. The temperature program was as follows: 25 cycles of $1 \mathrm{~min}$ at $94^{\circ} \mathrm{C}, 1 \mathrm{~min}$ at $65^{\circ} \mathrm{C}$ and $2 \mathrm{~min}$ at $72^{\circ} \mathrm{C}$. The PCR product, with a size of $1.6 \mathrm{~kb}$, was purified from an agarose gel with a QIAquick gel extraction kit (Qiagen), cloned into TA vector (TA cloning kit; Invitrogen) and analysed by restriction enzyme digestion. The $1.6 \mathrm{~kb}$ insert, corresponding to the $d n r F$ gene, was cut out from the TA vector by EcoRI digestion and cloned into the EcoRI site of pGEX-2T or pT7-7.

To induce expression of the GST-DnrF fusion protein, mid-log phase $\mathrm{DH} 5 \alpha(\mathrm{pLA}-4)$ cultures $\left(\mathrm{OD}_{600}=0.6\right)$ were grown in $2 \mathrm{mM}$ isopropyl- $\boldsymbol{\beta}$-D-thiogalactoside (IPTG; Boehringer Mannheim) for an additional $3 \mathrm{~h}$ at $37^{\circ} \mathrm{C}$. The fusion protein was extracted and purified using glutathione agarose (G-4510, Sigma) as described by Smith \& Johnson (1988).

The expression in E. coli of the unfused $\mathrm{DnrF}$ protein was achieved by the pT7-7 system. E. coli DH1 cells were first transformed with the pGP1-2 plasmid (Tabor \& Richardson, 1985) bearing the kanamycin-resistance gene. pGP1-2 enabled the expression of the T7 RNA polymerase under the control of the $\lambda P_{L}$ promoter. Kanamycin-resistant cells were transformed with $\mathrm{pFI} 15$ bearing the ampicillin-resistance gene and the entire $d n r F$ gene under the control of the $\phi 10$ promoter specifically recognized by the T7 RNA polymerase (Tabor \& Richardson, 1985). Double transformants were grown at $30^{\circ} \mathrm{C}$. For the induction of $d n r F, E$. coli DH1(pGP1-2/pFI 15) cells were grown in $2 \times$ YT medium (Sambrook et al., 1989) (made with $80 \mu \mathrm{g} \mathrm{ml}^{-1}$ of both kanamycin and ampicillin). At $\mathrm{OD}_{590}=3.0$ the temperature was raised to $42{ }^{\circ} \mathrm{C}$ for $30 \mathrm{~min}$, then the cells were grown for $120 \mathrm{~min}$ further at $30^{\circ} \mathrm{C}$.

For the bioconversion assay anthracyclines dissolved in DMSO at $50 \mu \mathrm{g} \mathrm{ml}^{-1}$ and NADPH ( $5 \mathrm{mM}$ final concentration) were added to a DH1(pGP1-2/pFI 15) induced culture and cells were grown for a further $60 \mathrm{~min}$ at $30^{\circ} \mathrm{C}$. The cultures were extracted and analysed by HPLC.

Enzymic assay for the DnrF protein with $E$. coli crude extracts. Induced E. coli DH1(pGP1-2/pFI 15) cells were harvested by centrifugation at $3000 \mathrm{~g}$ at $4{ }^{\circ} \mathrm{C}$, resuspended in 4 vols cold lysis buffer ( $25 \mathrm{mM}$ Tris/ $\mathrm{HCl}$ pH 8.0, $150 \mathrm{mM} \mathrm{NaCl}, 2 \mathrm{mM}$ EDTA), distupted by sonication and centrifuged at $15000 \mathrm{~g}$. The assay was performed by shaking the supernatant at $37^{\circ} \mathrm{C}$ for $60 \mathrm{~min}$ in $100 \mathrm{mM}$ potassium phosphate buffer $(\mathrm{pH} 7 \cdot 7)$ containing NADPH $(5 \mathrm{mM})$ and substrates (at the indicated concentrations) dissolved in DMSO. Further reaction was blocked by adding an equal volume of acetonitrile/methanol $(1: 1, \mathrm{v} / \mathrm{v})$. After vortexing and centrifugation, the supernatant was filtered and analysed by reverse-phase HPLC.

Enzymic assay for the Dnrf protein with $S$. lividans crude extracts. S. lividans (pFI 20) was grown in YEME medium (Hopwood et al., 1985a) for $76 \mathrm{~h}$, harvested by centrifugation, washed in PBS, resuspended in 4 vols lysis buffer and disrupted by sonication. After centrifugation at $15000 \mathrm{~g}$ the supernatant was used as a crude enzyme preparation.

HPLC analysis. Acetonitrile/methanol $(1: 1, \mathrm{v} / \mathrm{v})$ was used to extract the metabolites. The extracts were filtered by a Millex- 
GV $0.45 \mu \mathrm{m}$ filter (Millipore) before HPLC analysis. The metabolites were identified by HPLC with a reverse-phase Hypersil ODS-microbore column (Shandon). A linear gradient of $23-67 \%$ acetonitrile buffered at $\mathrm{pH} 2.5$ with $12.5 \mathrm{mM}$ sodium monobasic phosphate was applied for $52 \mathrm{~min}$ at a flow rate of $0.125 \mathrm{ml} \mathrm{min}^{-1}$. The elution profile was monitored with a Hewlett-Packard diode array detector at 488, 424 or $254 \mathrm{~nm}$.

Streptomyces transformation and bioconversion experiments. Protoplasts were produced from S. lividans TK23 grown in YEME medium supplemented with $0.5 \%$ glycine at $28^{\circ} \mathrm{C}$ as described by Hopwood et al. (1985a) and regenerated on R2YE agar. $S$. lividans transformants were selected and maintained on thiostrepton at $50 \mu \mathrm{g} \mathrm{ml}^{-1}$.

S. lividans TK23(pFI 14) or S. lividans TK23(pFI 20) was grown for $48 \mathrm{~h}$ in YEME medium at $30^{\circ} \mathrm{C}$. One millilitre of the culture was used to inoculate $25 \mathrm{ml}$ fermentation medium described by McGuire et al. (1979). Anthracyclines were added to $68 \mathrm{~h}$ cultures and, after 24 h, $650 \mathrm{mg}$ oxalic acid was added. Cultures were incubated at $50{ }^{\circ} \mathrm{C}$ for $45 \mathrm{~min}$, then the crude extracts were prepared and analysed by HPLC.

Preparation of antisera to the GST-DnrF fusion protein. Antibodies against the purified recombinant protein were produced in 6 week old Balb/c female mice according to the following protocol: the first intraperitoneal shot contained $50 \mu \mathrm{g}$ purified recombinant protein in $50 \mu \mathrm{l}$ sterile PBS plus $50 \mu \mathrm{l}$ complete Freund adjuvant. Four more injections, at 2 week intervals, were done with the same amount of antigen but without adjuvant. In Western blot analysis the serum was used at a $1: 1000$ dilution.

Protein analysis. SDS-PAGE and Western blot analysis were performed as previously described (Buvoli et al., 1990). Mouse anti-GST-DnrF antibodies were used at a 1:1000 dilution and revealed by alkaline-phosphatase-conjugated anti-mouse IgG (Promega).

\section{RESULTS}

\section{Cloning and sequencing of the aklavinone 11-hydroxylase gene}

We previously reported the isolation and characterization of ric1, a $5.7 \mathrm{~kb}$ DNA fragment from the $S$. peucetius 7600 mutant, which contains the Dxr-Dnr resistance gene (drr $A B)$. Bioconversion experiments with S. lividans TK23 (ric1) suggested the presence, close to $\operatorname{dr} A B$, of the $d n r F$ gene, which converts aklavinone (a yellow compound) to $\varepsilon$-rhodomycinone (red) via 11-hydroxylation (Colombo $e t$ al., 1992).

We have now mapped, by means of the same bioconversion assay, the $d n r F$ gene within pWHM603 (Guilfoile \& Hutchinson, 1991), which contains part of the Dnr cluster from S. peucetius ATCC 29050 (Fig. 1). The region conferring the ability to $S$. lividans $\mathrm{TK} 23$ to convert the added aklavinone to $\varepsilon$-rhodomycinone $(80 \%$ conversion) is located in a $2.2 \mathrm{~kb}$ fragment (plasmid pFI 14) (Fig. 1).

The pFI 14 insert was sequenced and, as shown in Fig. 2, the first $118 \mathrm{nt}$ correspond to the $5^{\prime}$ end of the $\operatorname{drr} A B$ gene (non-coding strand) (Guilfoile \& Hutchinson, 1991). The ORF for the $d n r F$ gene was identified on the basis of previously reported considerations (Bibb et al., 1984) about the distribution of $\mathrm{G}+\mathrm{C}$ content across codons in Streptomyces genes. Thus a region spanning from position 352 to 1822 contains the $d n r F$ gene (Fig. 2), beginning with a putative GTG translation start codon and ending with a TGA stop codon. A plausible ribosome-binding site (GGAGG) (Strohl, 1992) is located $6 \mathrm{nt}$ upstream of the GTG codon. The first $237 \mathrm{nt}$ of the ORF were previously sequenced by Guilfoile \& Hutchinson (1991) and proposed to be part of the $d n r F$ gene.

The $\operatorname{dr} A B$ and $d n r F$ genes are separated by a spacer of $233 \mathrm{nt}$ that contains the $\operatorname{dr} A B$ promoter (Guilfoile \& Hutchinson, 1991) and most likely the divergent $d n r F$ promoter. This region is significantly AT-richer than the remaining part of the clone ( $\mathrm{A}+\mathrm{T} 46 \%$ vs $30 \%)$.

\section{Analysis of the deduced dnrF gene product}

The $d n r F$ gene encodes a protein of 489 amino acids with a predicted molecular mass of $52 \mathrm{kDa}$. Sequence comparison with the GenBank database performed by the FASTA and TFASTA programs showed significant
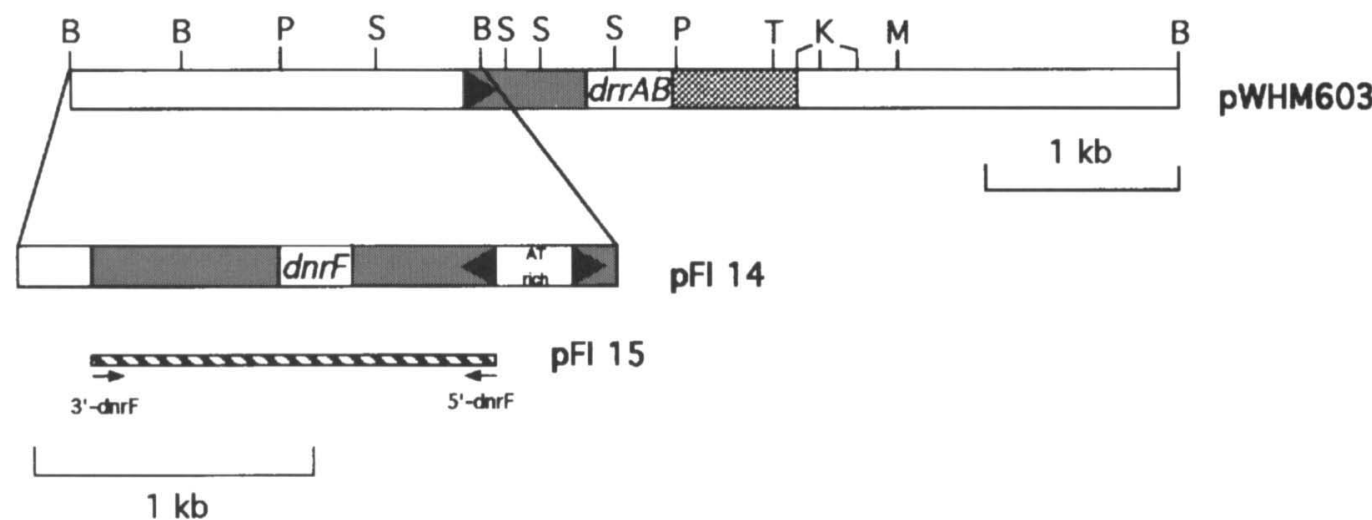

Fig. 1. Schematic representation of the pWHM603, pFI 14 and pFI 15 inserts. The position of the drrAB and the dnrF genes is indicated by grey boxes. Black arrowheads indicate the direction of transcription. The AT-rich spacer containing the promoters of the two genes is indicated. The position of the two primers used to amplify the dnrF ORF is also shown. Restriction enzyme abbreviations: B, BamHI; K, Kpnl; M, Mlul; P, Pstl; S, Sphl; T, Sstl. 
1072

1132

1192

1252

1312

1372

1432

1492

1552

1612

1672

1732

1792

1822

1901

1980

2059

2138 g gat ccc gta gac gag acc gec cGg cac ott gag tic cag gCC gtc cac cGC CCT CG CCC GT GTA GAC CTT GAC GAG ACC GGA CGT TTC GAT GOC CCG TGT CGG CTG CGT GT CAC) CTAACGCCCCAGTAGTCACATGQAGCGGACMGCGGCACTGM MGTATTTCGTCATCGGGTTCACGTTG AGTACCGTAGCCCCCUTGAGGACACTTCATGGCCGCGATGGCTTCGTCGCCGAGCCATITTCGTACGGGGCTCCAC

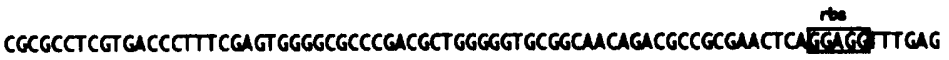

$\overrightarrow{G T G}$ GCC TTG ACG MG CCG GAT GTC GAT GT CTC GTG GTG GGC GGC GGT CTC GGG GGG CTG

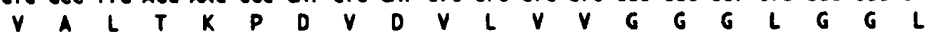
TCC ACC GCC CTG TIC CTC GCC CGC CGG GGG GCG CGG GTC CTG CTG GTG GAG COG CAT GCC $\begin{array}{llllllllllllllllllll}S & T & A & L & F & L & A & R & R & G & A & R & V & L & L & V & E & R & H & A\end{array}$ ACC ACC TCG GTC CTG CCC MAG GCG GCA GGC CAG MC CCG CGC ACC ATG GM CTG TTC CGC $\begin{array}{llllllllllllllllllll}S & T & S & V & L & P & K & A & A & G & Q & N & P & R & T & A & E & L & F & R\end{array}$ TTC GGC GGC GTG GCC CAC GAG ATC CTG GCC ACG GAC GAC ATC CGC GGC GCC CAG GGC GAC $\begin{array}{llllllllllllllllllll}F & G & G & V & A & 0 & E & I & L & A & T & D & D & I & R & G & A & Q & G & D\end{array}$ TTC ACC ATC MG GTC GTG GAG CGC GTG GGC GGT CGC GTC CTG CAC AGC TTC GCG GAG AGC $\begin{array}{llllllllllllllllllll}F & T & I & K & V & V & E & R & V & G & G & R & V & L & H & S & F & A & E & S\end{array}$ TTC GAG GA CTG GTC GG GCG ACG GM CAG TGC ACG CCC ATG CCC TGG GCG CTC GCT CCC

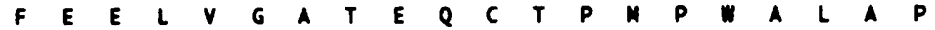
CAG GAC CGG GTG GAG CCC GTC CTG GTG GCC CAC GCC GCC MAG CAC GGC GCG GAG ATC CGG $\begin{array}{llllllllllllllllllll}Q & D & R & V & E & P & V & L & V & A & H & A & A & K & H & G & A & E & I & R\end{array}$ TTC GCC ACC GU CTG ACC TCC TTC CAG GCG GSC CAC GAC GGT GTC ACG GCC COC CTG CGC F A T E L T S F $Q$ T A G GAC CTG GGC ACG GGA GCG GAG AGC ACC GTG AGC GCC CGC TAC CTG GTC GCC GCC GAC GGA $\begin{array}{lllllllllllllllllll}D & L & G & T & G & E & S & T & V & S & A & R & Y & L & V & A & A & D & G\end{array}$ CCC CGC AGC GCG ATC CGG GAG AGC CTG GGC ATC ACC CGG CAC GGT CAC GCC ACC CTG GCC $\begin{array}{llllllllllllllllllll}P & R & S & A & I & R & E & S & L & G & I & T & R & H & G & H & G & T & L & A\end{array}$ CAC TTC ATG GGC GTC ATC TTC GAG GCC GAC CTC ACC GCC GTC GTA CCG CCC GGG TCC ACC

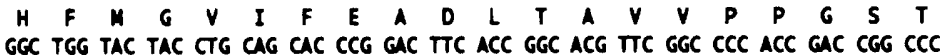
$\begin{array}{llllllllllllllllllll}G & W & Y & Y & L & Q & H & P & D & F & T & G & T & F & G & P & T & D & R & P\end{array}$ MC CGG CAC ACC TTC TAC GTC GCT ACG ACC CCT GA CGC GOC GAG AGG CCG GAG GAC TAC

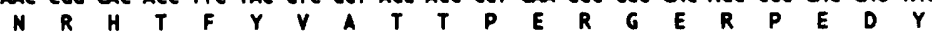
aCA CCG CIG CGC TGC ACC GAG CTG ATC CGG CTG GCT GTC GAC GCG CCC GEG CTC GTC CCG $\begin{array}{llllllllllllllllllll}T & P & Q & R & C & T & E & L & I & R & L & A & V & D & A & P & G & L & V & P\end{array}$ GaC ATC CTC CAC ATC CAG GCC TGG GaC ATG GCG GCG TAC ATC GCC GAC CGG TGG CGC GA

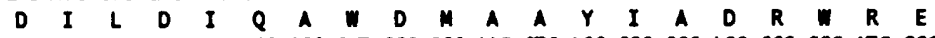
GGG CCG GTG CTG CTG GT GGC GAT GCC GCC MG GTC ACC CCG CCC ACC GCG GGC ATG GGC $\begin{array}{llllllllllllllllllll}G & P & V & L & L & V & G & D & A & A & K & V & T & P & P & T & G & G & M & G\end{array}$ GEC MAC ACC GCC ATC GCC GAC GGG TTC GAC GTG GCC TGG MGG CTG GCC GCC GTG CTG CGC $\begin{array}{llllllllllllllllllll}G & N & T & A & I & G & D & G & F & D & V & A & & K & L & A & A & V & L & R\end{array}$ GCC GAG GCG GGC GAG CGG CTC CTC GAC AGC TAC GGG GCG GAG CGG TCG CTC GTG TCC CGC $\begin{array}{llllllllllllllllllll}G & E & A & G & E & R & L & L & D & S & Y & G & A & E & R & S & L & V & S & R\end{array}$ CTC GTC GTC GAC GAG TCA CTC GCC ATC TAC GCC CAG CGC ATG GCT CCC CAC CTG CTC GGC $\begin{array}{llllllllllllllllllll}L & V & V & D & E & S & L & A & I & Y & A & Q & R & A & A & P & H & L & L & G\end{array}$ ACC GT CCC GAG GA CGC GGT ACG GCG CAG GTC GTC CTG GGC TTC CGC TAC CGC TCC ACC $S V V P$ E E R G T A Q $R$ V V GCC GTC CCC GCC GAG GAC GAC GAC CCC GAG CCG ACC GAG GAT CCG CQA CCC CCG TCC GGG

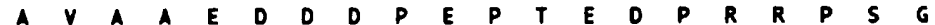
CCC CCC GGC TTC CGC GCA CCC CAC GTC TGG ATC CM CAG GAC GGC ACA CGO CGT TCC ACC $\begin{array}{llllllllllllllllllll}R & P & G & F & R & A & P & H & V & W & I & E & Q & D & G & T & R & R & S & T\end{array}$ GT GAG TTG TTC GGC GAC TGC TGG GT CTC CTG GCC GCA CCG GAG GGC GEC GCC TGG CCC

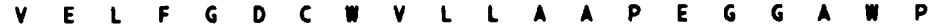
GGG CGG CCG CCC GCG CCG CCG CGG ATC TGG GCG TCC GCC TCG ACG TCC ATC TCG TCG GCC $\begin{array}{llllllllllllllllllll}G & R & P & P & A & P & P & R & I & A & A & S & A & S & T & S & I & S & S & A\end{array}$ GCG ATG TCG CCG CCC CCT CCG GCG MC TGA

A M S P P P P A N

CGCGGACCTACGGGATCGGCCGGGCGGGGGCCAGCTTGGTCCGCCCGGACGGCGTGGTCCCTGGCGTACGGCAGTAGC ecCGgGaGCGGaGGCCAGGACCAGCTGAGCACCGTGCTCACCCGGCTGCTGCCCCGCTGACCGGAGCGTCCCGCGTCG GCGGCGCCACCACGGAGCGT CCGCGCCCGGCGCGCGGCTCGGGCAGCCGCTCCGACACTCCTGTATGTMTGAT CAGTCAGCCGGCTCGTCACCTCGMCTCGCGCCGMCATCCCGATGGTGGCGCCACCCACTCCAGCEGTCGCG GCCGUCGCAGCCGCATGTCCGTGGTCACCGCTGTGGGATTCCGTCGCGCGGCGGATCC
Fig. 2. Nucleotide sequence of the $2 \cdot 2 \mathrm{~kb}$ insert from plasmid pFI 14 with the deduced amino acid sequence of the dnrF ORF in the single-letter code. The putative RBS of the dnrF gene is boxed. The first $118 \mathrm{nt}$ are complementary to the $5^{\prime}$ end of the drrAB ORF (codon arrangement is represented). resemblance to two groups of hydroxylase enzymes (Fig. 3): those catalysing the introduction of hydroxyl groups into polycyclic aromatic polyketide antibiotics (Blanco et al., 1993; Decker et al., 1993) and those involved in catabolism of aromatic compounds in different organisms (Blanco et al., 1993; Kalin et al., 1992; Nurk et al., 1991; Perkins et al., 1990; Weijer et al., 1982). No similarity with P-450 cytochromes (Andersen et al., 1993; Stassi et al.,
1993; Weber et al., 1991) involved in the hydroxylation of erythromycin, or with act $V A$ gene products (Caballero $e t$ al., 1991), responsible for hydroxylation of the ring structures in actinorhodin biosynthesis, was found. As shown in Fig. 3, the DnrF enzyme contains two motifs that are common to a number of FAD- and NADPHdependent enzymes. The first motif, located at the $\mathrm{N}$ terminus of the protein (amino acids 3-47), is the so called 

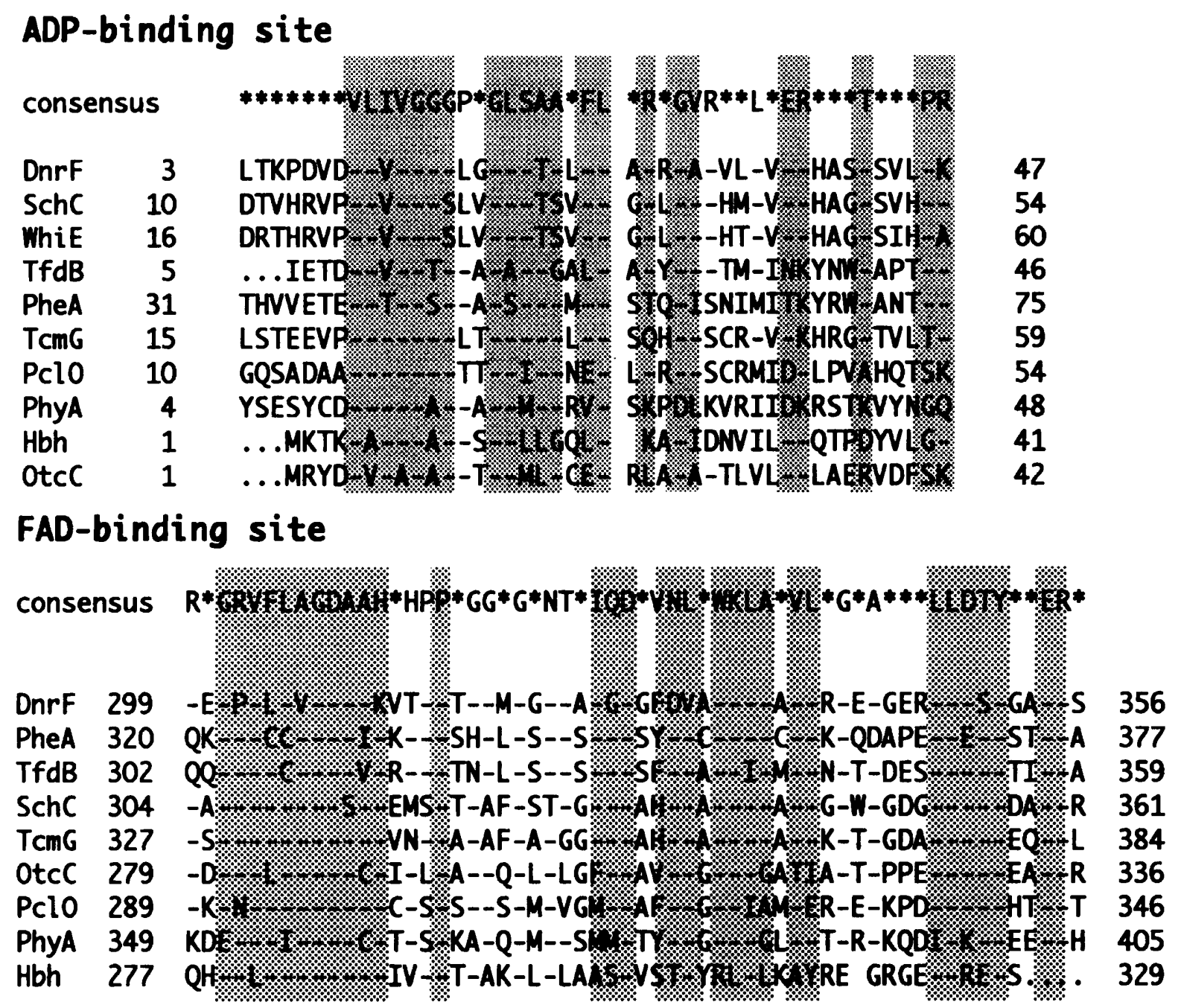

Fig. 3. Comparison of the deduced amino acid sequence of the dnrF gene with sequences of amino acids encoded by other hydroxylase genes. The alignment shows the similarity among the dnrF product and different hydroxylases in the 'ADP-binding site' and in the 'FAD-binding site' motifs, present in many FAD- and NADPH-dependent enzymes. The amino acids in the consensus sequence (on top of each motif) are the ones present in at least half of the compared protein sequences. Asterisks indicate the non-conserved positions. Dashes in the protein sequences represent amino acids identical to the consensus. Grey boxes highlight the more conserved regions. The hydroxylase proteins compared are as follows: SchC (Blanco et al., 1993); WhiE (Blanco et al., 1993); TfdB (Perkins et al., 1990); PheA (Nurk et al., 1991); TcmG (Decker et al., 1993); PclO (Blanco et al., 1993); PhyA (Kalin et al., 1992); Hbh (Weijer et al., 1982); OtcC (Blanco et al., 1993).

$\beta \alpha \beta$ fold and is involved in binding of the ADP moiety of FAD (Wierenga et al., 1986). The second motif seems to be important in binding the ribityl chain of the flavin moiety of FAD (Eggink et al., 1990; Russel \& Model, 1988). These similarities further support the conclusion that the $d n r F$ gene encodes for the aklavinone 11hydroxylase.

\section{Expression of the dnrF gene in Streptomyces and in E. coli}

We stated above that, upon transformation with pFI 14, $S$. lividans acquired the ability to bioconvert aklavinone to $\varepsilon$-rhodomycinone. Incubations for $1 \mathrm{~h}$ gave 11 -hydroxylation of $10 \%$ of the aklavinone $\left(50 \mu \mathrm{g} \mathrm{ml}^{-1}\right)$ added to the medium. Complete conversion was seen after $6 \mathrm{~h}$. Since this could be due to low levels of gene expression, we cloned the $d n r F$ gene (1605 nt) into the pWHM3 vector under the control of the strong ermE* promoter (pFI 20 plasmid; see Methods). S. lividans(pFI 20) converted $100 \%$ of aklavinone $\left(50 \mu \mathrm{g} \mathrm{ml}^{-1}\right)$ to $\varepsilon$ rhodomycinone in $1 \mathrm{~h}$ incubations. Moreover, this transformant also catalysed the hydroxylation of compounds biochemically derived from aklavinone (see Table 1 and Fig. 4), but it had no activity with molecules other than anthracyclines (Table 1).

For an initial biochemical characterization we expressed the $d n r F$ gene in E. coli as a fusion with GST. To this aim the $\operatorname{dnr} F$ gene was PCR-amplified and cloned into the EcoRI site of the pGEX-2T vector (see Methods). The 
Table 1. Percentage in vitro and in vivo conversion of different chemical species

\begin{tabular}{|c|c|c|c|c|c|}
\hline \multirow[t]{2}{*}{ Chemical species } & \multirow[t]{2}{*}{$\begin{array}{c}\text { Concn } \\
\left(\mu \mathrm{g} \mathrm{ml}^{-1}\right)\end{array}$} & \multicolumn{2}{|c|}{ In vitro conversion } & \multicolumn{2}{|c|}{$\begin{array}{c}\text { In vivo cell } \\
\text { bioconversion }\end{array}$} \\
\hline & & $\begin{array}{l}\text { E. coli } \\
\text { pFI } 15\end{array}$ & $\begin{array}{c}\text { S. lividans } \\
\text { pFI } 20\end{array}$ & $\begin{array}{l}\text { E. coli } \\
\text { pFI } 15\end{array}$ & $\begin{array}{c}\text { S. lividans } \\
\text { pFI } 20\end{array}$ \\
\hline Aklavinone & 50 & $100 \%$ & $100 \%$ & $80 \%$ & $100 \%$ \\
\hline 10-Decarbomethoxy-aklavinone & 50 & & & & $90 \%$ \\
\hline 11-Deoxycarminomycinone & 50 & $70 \%$ & $100 \%$ & $70 \%$ & $100 \%$ \\
\hline 11-Deoxydaunomycinone & 50 & & $10 \%$ & & $10 \%$ \\
\hline 11-Deoxy-4-demethyl-adriamycinone & 30 & $10 \%$ & $10 \%$ & $10 \%$ & $10 \%$ \\
\hline 11-Deoxycarminomycin & 30 & $0 \%$ & $0 \%$ & $0 \%$ & $0 \%$ \\
\hline 11-Deoxydaunomycin & 30 & $0 \%$ & $0 \%$ & $0 \%$ & $0 \%$ \\
\hline 11-Deoxy-4-demethyl-daunomycin & 30 & $0 \%$ & $0 \%$ & $0 \%$ & $0 \%$ \\
\hline 1,8-Dihydroxyanthraquinone & 50 & $0 \%$ & $0 \%$ & $0 \%$ & $0 \%$ \\
\hline
\end{tabular}

GST-DnrF fusion, purified on a glutathione agarose column, was assayed for its ability to convert aklavinone to $\varepsilon$-rhodomycinone and used as antigen to raise polyclonal antibodies in a mouse. Since the fusion protein did not show any hydroxylase activity (data not shown), we cloned the $d n r F$ gene into the pT7-7 vector that allowed the expression of an unfused $\mathrm{DnrF}$ protein. Interestingly, upon transformation with this construct (pFI 15), E. coli was able to bioconvert aklavinone to $\varepsilon$ rhodomycinone (Table 1). Furthermore, the cell extract prepared from E. coli(pFI 15) (see Methods) catalysed the aklavinone 11-hydroxylation in a NADPH-dependent reaction, as determined by HPLC analysis (Fig. 5). Both E. coli(pFI 15) cells and crude extracts were active on substrates other than aklavinone, and showed the same specificity observed with S. lividans( $\mathrm{pFI} 20$ ) cells and extracts (Table 1).

To confirm the expression of the DnrF protein in heterologous systems we carried out Western blot experiments using the antibodies raised to the GST-DnrF fusion. As shown in Fig. 6, a protein with an apparent molecular mass of $52 \mathrm{kDa}$ was recognized in extracts from S. peucetius ATCC 29050, E. coli DH1(pFI 15) and S. lividans TK23(pFI 20) while no signal was detected in extracts from E. coli DH1(pT7-7) and S. lividans TK23. The same protein was present in the $S$. peucetius 7600 strain but absent in the non-producing S. peucetius 9700 mutant. Moreover, no protein band was recognized in extracts of the S. lividans TK23(pFI 14) strain, which indicates a low level of $d n r F$ expression. This result is compatible with the reduced rate of bioconversion observed.

\section{DISCUSSION}

In this paper we report the sequencing and expression of the $d n r F$ gene from $S$. peucetius ATCC 29050. The gene belongs to the Dxr-Dnr biosynthetic gene cluster and, as previously suggested (Colombo et al., 1992), it is closely associated with the Dxr-Dnr resistance gene $\operatorname{drr} A B$. The $d n r F$ gene encodes an enzyme of 489 amino acids that catalyses the conversion of aklavinone to $\varepsilon$-rhodomycinone via 11-hydroxylation. Accordingly, the analysis of the deduced DnrF protein sequence revealed the presence of two motifs common to a number of FAD- and NADPH-dependent hydroxylases involved in catabolism of aromatic compounds. As shown in Fig. 3, both regions are formed by alternating divergent and conserved sequences. In particular, the more C-terminal motif seems to be formed by three conserved regions separated by amino acid stretches containing Gly and Pro, two residues very often associated with protein bending. The first conserved box is the only one where Cys or His can be found. It is intriguing to observe that $\mathrm{DnrF}$ is the only protein among those shown that lacks these residues. We think that these differences could reflect enzymic specificity and, at the same time, can be used as a measure of the relatedness of different members of this protein family.

For preliminary biochemical characterization we expressed the $d n r F$ gene in both $S$. lividans and E. coli cells. In vitro conversion assays carried out with crude extracts demonstrated that the 11-hydroxylation reaction is NADPH-dependent. DnrF has a significant substrate specificity, since it is completely inactive on molecules other than anthracyclines (see Table 1).

Aklavinone, the natural substrate, is a key intermediate in the biosynthesis of Dxr and Dnr and requires several successive chemical modifications such as hydroxylation, glycosylation, oxidation and methylation. DnrF catalyses the first among these modifications, i.e. 11-hydroxylation of aklavinone (yellow) to $\varepsilon$-rhodomycinone (red). The fact that DnrF acts early in the metabolic pathway of Dnr biosynthesis does not mean that 11-hydroxylation is required for all the successive inodifications to take place. For instance, the $\operatorname{dnr} F 7800$ mutant is able to produce 11-deoxydaunorubicin (yellow) and 11-deoxydoxorubicin (yellow). These results support the alternative hypothesis that the temporal order is simply linked to the substrate specificity of the enzyme because DnrF utilizes the 11- 
Aklavinone

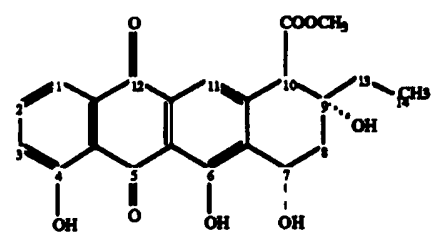

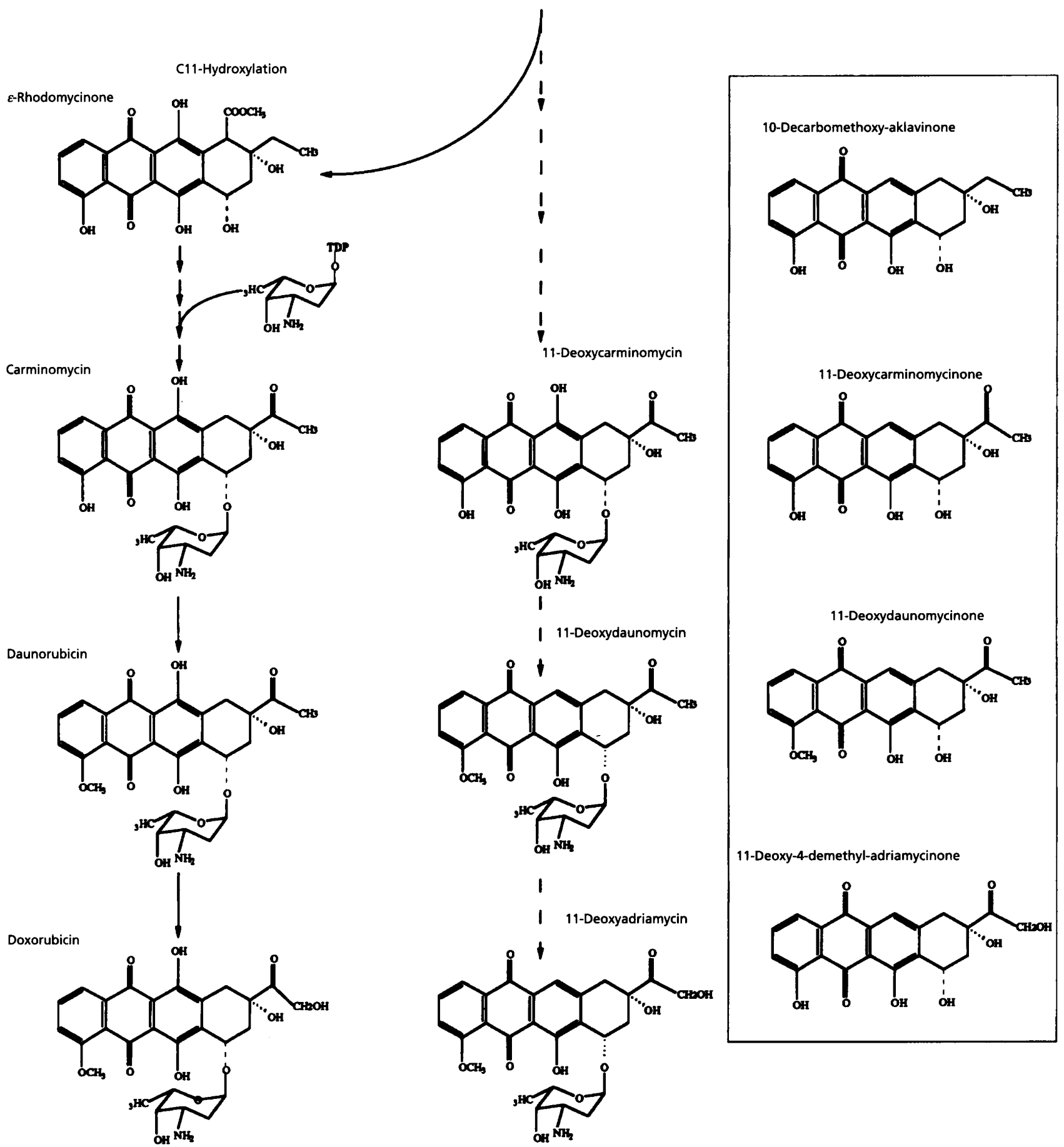

Fig. 4. Schematic Dnr-Dxr biosynthetic pathway (red compounds) and the structural formula of each compound. The enzymic reaction carried out by the $d n r F$ gene product is indicated. Broken arrows indicate yellow compounds derived from the biosynthetic intermediates of the yellow mutant S. peucetius 7800 . The box contains the aglycons compounds. 
(a)

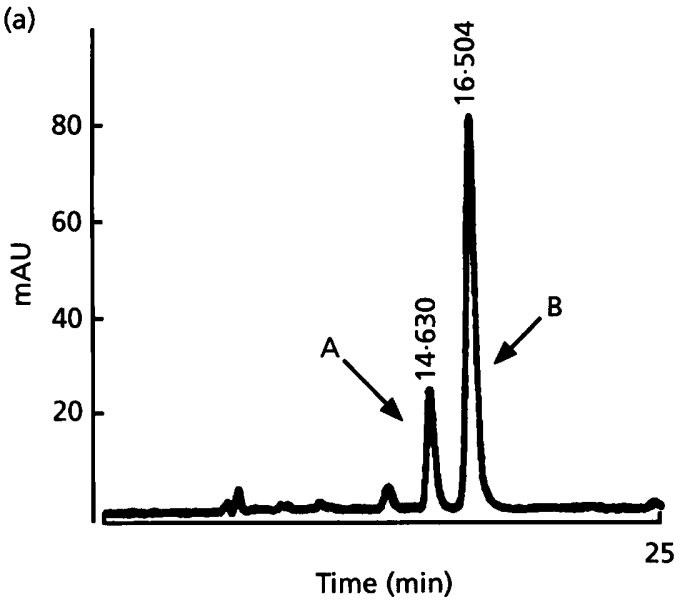

(b)

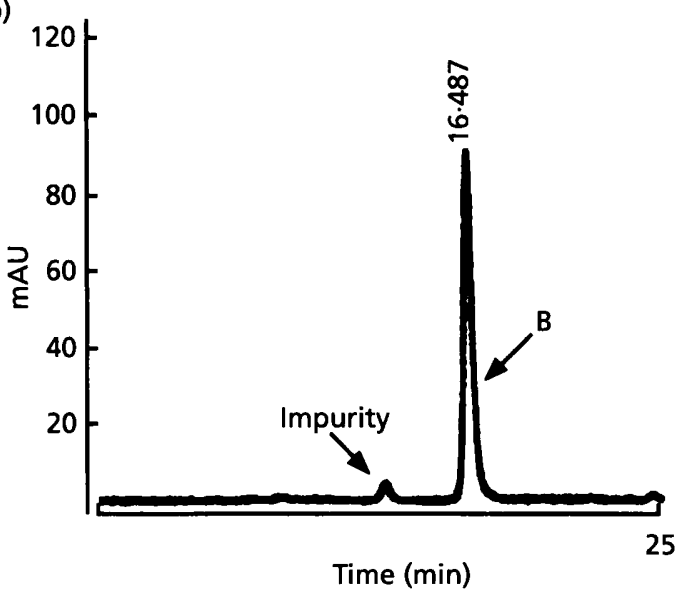

(c)

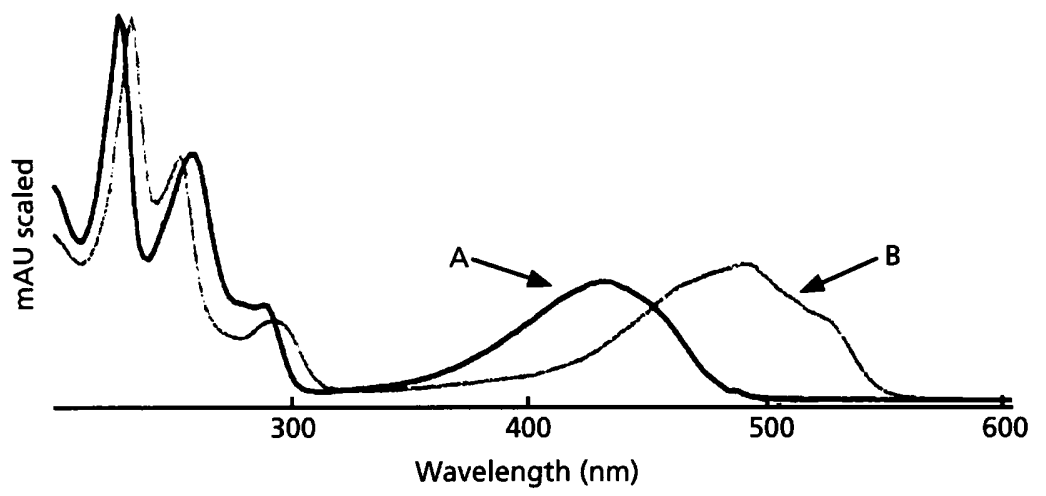

Fig. 5. HPLC analysis of aklavinone bioconversion by $E$. coli(pFI 15) (a) and S. lividans(pFI 20) (b) at $254 \mathrm{~nm}$. (c) Aklavinone and $\varepsilon$-rhodomycinone relative spectra of the samples from (a). A, Aklavinone; B, $\varepsilon^{-}$ rhodomycinone.

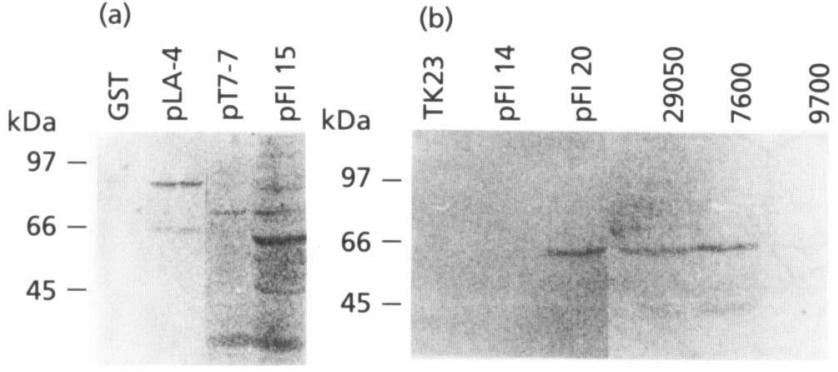

Fig. 6. Western blot analysis of $E$. coli and Streptomyces protein extracts with anti-GST-DnrF mouse polyclonal antibodies. Lanes (a): GST, purified glutathione S-transferase; pLA-4, GST-DnrF fusion protein purified from $E$. coli $\mathrm{DH} 5 \alpha(\mathrm{pLA}-4)$; pT7-7, E. coli DH1(pT7-7) total extract; pFI 15, E. coli DH1(pFI 15) total extract. Lanes (b): TK23, total extract from S. lividans TK23; pFI 14, total extract from $S$. lividans TK23(pFI 14); pFI 20, total extract from S. lividans TK23(pFI 20); 29050, total extract from S. peucetius ATCC 29050; 7600 and 9700 , total extracts from 7600 and 9700 mutants derived from S. peucetius ATCC 27952. The positions of the molecular mass markers are indicated on the left of each panel.

deoxy compounds, downstream of aklavinone in the biosynthetic pathway, much less efficiently than aklavinone. In particular, the enzyme is completely inactive on the C-7 glycosylated intermediates (compare the 11-deoxycarminomycin to 11-deoxycarminomycinone conversion in Table 1). Our data also indicate that modifications of the aklavinone molecule can influence the efficiency of the hydroxylation carried out by DnrF. While molecules modified in positions $\mathrm{C}-10$ and $\mathrm{C}-13$ are hydroxylated as efficiently as aklavinone (see 11deoxycarminomycinone conversion, Table 1 and Fig. 4), molecules 14-hydroxylated or 4-methylated are very poor substrates (see 11-deoxy-4-demethyladriamycinone and 11-deoxydaunomycinone conversion, Table 1 and Fig. 4). The hydroxyl group in position 11 of anthracyclines seems to have a primary biological role, since all the red compounds (11-hydroxylated) are more toxic for Streptomyces and more cytotoxic for animals than the yellow 11-deoxy analogues (Oki, 1988).

The $\operatorname{dr} A B$ gene is one, and probably the most important, of the Streptomyces genes conferring resistance to Dxr and Dnr (Colombo et al., 1992; Guilfoile \& Hutchinson, 1991). We have previously shown that the $\operatorname{dr} A B \mathrm{mRNA}$ appears in parallel with Dnr production, suggesting that $\operatorname{drr} A B$ gene expression is regulated at the transcriptional level (Colombo et al., 1992). As suggested previously (Guilfoile \& Hutchinson, 1991) and demonstrated in this paper, the $\operatorname{dr} A B$ and $d n r F$ genes are transcribed in opposite directions and are separated by a spacer of $233 \mathrm{nt}$ 
where the promoters of both genes are located. It is conceivable that this arrangement can be relevant for a possible coordinate expression of the two genes, as already demonstrated for many prokaryotic and eukaryotic divergent promoters (Beck \& Warren, 1988). One indication supporting this idea derives from the $d n r F 7800$ mutant that produces 11-deoxydaunorubicin and 11deoxydoxorubicin. This mutant fails to express the $\operatorname{dr} A B$ gene and is sensitive to Dxr and Dnr. It is reasonable to think that the $\operatorname{dr} A B$ gene is primarily involved in conferring resistance to 11 -hydroxylated anthracyclines and therefore is absolutely required after the activation of the $d n r F$ gene.

Altogether these considerations point to the $d r r A B-d n r F$ gene system as a possible target for a major control point in the anthracycline biosynthetic pathway, a hypothesis that deserves further analysis.

\section{ACKNOWLEDGEMENTS}

This work was supported by a Biotechnology P.N.R. contract between M.U.R.S.T. and Farmitalia Carlo Erba. We thank G. Rivola for the 11-deoxyanthracyclines and for helpful discussions. We also thank C. R. Hutchinson for providing pWHM603 and for helpful suggestions. D.G. and M.S. are supported by a fellowship of the National Research Council Progetto Finalizzato Ingegneria Genetica and 'A. Buzzati 'Traverso' foundation, respectively.

\section{REFERENCES}

Andersen, J. F., Tatsuta, K., Gunji, H., Ishiyama, T. \& Hutchinson, C. R. (1993). Substrate specificity of 6-deoxyerythronalide B hydroxylase, a bacterial cytochrome P450 of erythromycin A biosynthesis. Biochemistry 32, 1905-1913.

Arcamone, F. (1981). Doxorubicin. Med Chem Ser Monogr 17, 25-31.

Beck, C. F. \& Warren, R. A. J. (1988). Divergent promoters, a common form of gene organization. Microbiol Rev 52, 318-326.

Bibb, M. J., Findlay, P. R. \& Johnson, M. W. (1984). The relationship between base composition and codon usage in bacterial genes and its use for the simple and reliable identification of protein-coding sequences. Gene 30, 157-166.

Blanco, G., Pereda, A., Brian, P., Méndez, C., Chater, K. F. \& Salas, J. A. (1993). A hydroxylase-like gene product contributes to synthesis of a polyketide spore pigment in Streptomyces balstedii. $J$ Bacteriol 175, 8043-8048.

Buvoli, M., Cobianchi, F., Bestagno, M., Mangiarotti, A., Bassi, M. T., Biamonti, G. \& Riva, S. (1990). Alternative splicing in the human gene for the core protein A1 generates another hnRNP protein. EMBO J 9, 1229-1235.

Caballero, J. L., Martinez, E., Malpartida, F. \& Hopwood, D. A. (1991). Organization and functions of the act $V A$ region of the actinorhodin biosynthesis gene cluster of Streptomyces coelicolor. Mol \& Gen Genet 230, 401-412.

Cassinelli, G., Grein, A., Masi, P., Suarato, A., Bernardi, L., Arcamone, F., Di Marco, A., Casazza, A. M., Pratesi, G. \& Soranzo, C. (1978). Preparation and biological evaluation of 4-Odemethyldaunorubicin (carmynomycin I) and of its 13dihydroderivate. J Antibiot 31, 178-184.

Colombo, A. L., Solinas, M. M., Perini, G., Biamonti, G., Zanella, G., Caruso, M., Torti, F., Filippini, S., Inventi-Solari, A. \& Garofano, L. (1992). Expression of doxorubicin-daunorubicin resistance genes in different anthracycline-producing mutants of Streptomyces peucetius. J Bacteriol 174, 1641-1646.

Crespi-Perellino, N., Grein, A., Merli, S., Minghetti, A. \& Spalla, C. (1982). Biosynthetic relationships among daunorubicin, doxorubicin and 13-dihydrodaunorubicin in Streptomyces peucetius. Experientia 38, 1455-1456.

Decker, H., Motamedi, H. \& Hutchinson, C. R. (1993). Nucleotide sequences and heterologous expression of tcm $G$ and $t \mathrm{~cm} P$, biosynthetic genes for tetracenomycin C in Streptomyces glaucescens. $J$ Bacteriol 175, 3876-3886.

Deng, Z., Kieser, T. \& Hopwood, D. A. (1987). Activity of a Streptomyces transcriptional terminator in Eschericbia coli. Nucleic Acids Res 15, 2665-2675.

Eggink, G., Engel, H., Vriend, G., Terpstra, P. \& Witholt, B. (1990). Rubredoxin reductase of Pseudomonas oleovorans: structural relationship to other flavoprotein oxidoreductases based on one NAD and two FAD fingerprints. $J$ Mol Biol 212, 135-142.

Floss, H. G. \& Strohl, W. R. (1991). Genetic engineering of hybrid antibiotics - a progress report. Tetrabedron 47, 6045-6058.

Gramajo, H. C., White, J., Hutchinson, C. R. \& Bibb, M. J. (1991). Overproduction and localization of the components of the polyketide synthase of Streptomyces glaucescens involved in the production of tetracenomycin C. J Bacteriol 173, 6475-6483.

Grein, A., Spalla, C., Di Marco, A. \& Canevazzi, G. (1963). Descrizione e caratterizzazione di un attinomicete (Streptomyces peucetius sp. nova) produttore di una sostanza ad attività antitumorale: la daunorubicina. G Microbiol 11, 109-118.

Guilfoile, P. G. \& Hutchinson, C. R. (1991). A bacterial analog of the $m d r$ gene of mammalian tumor cells is present in Streptomyces peucetius, the producer of daunorubicin and doxorubicin. Proc Natl Acad Sci US A 88, 8553-8557.

Hanahan, D. (1983). Studies on transformation of Escherichia coli with plasmids. $J$ Mol Biol 166, 557-580.

Hopwood, D. A., Bibb, M. J., Chater, K. F., Kieser, T., Bruton, C. J., Kieser, H. M., Lydiate, D. J., Smith, C. P., Ward, J. M. \& Schrempf, H. (1985a). Genetic Manipulation of Streptomyces: a Laboratory Manual. Norwich, UK: John Innes Foundation.

Hopwood, D. A., Malpartida, F., Kieser, H. M., Ikeda, H., Duncan, J., Fujii, I., Rudd, B. A. M., Floss, H. G. \& Omura, S. (1985b). Production of 'hybrid' antibiotics by genetic engineering. Nature 314, 642-643.

Hutchinson, C. R. (1992). Recombinant DNA and the development of antitumor and other antibiotics produced by Actinomycetes. Pharm Technol 16, 22-31.

Kalin, M., Neujahr, H. Y., Weissmahr, R. N., Sejlitz, T., Jઠbhl, R., Fiechter, A. \& Reiser, J. (1992). Phenol hydroxylase from Trichosporon cutaneum: gene cloning, sequence analysis, and functional expression in Escherichia coli. J Bacteriol 174, 7112-7120.

Madduri, K., Torti, F., Colombo, A. L. \& Hutchinson, C. R. (1993). Cloning and sequencing of a gene encoding carminomycin 4-Omethyltransferase from Streptomyces peucetius and its expression in Escherichia coli. J Bacteriol 175, 3900-3904.

McGuire, J. C., Hamilton, B. K. \& White, R. J. (1979). Approaches to development of the daunorubicin fermentation. Process Biochem $14,2-5$.

Myers, C. E., Mimnaugh, E. G., Yeh, G. C. \& Sinha, B. K. (1988). Biochemical mechanisms of tumor cell kill by anthracyclines. In Antbracycline and Antbracenedione-Based Anti-Cancer Agents, pp. 527-569. Edited by J. W. Lown. Amsterdam: Elsevier.

Nurk, A., Kasak, L. \& Kivisaar, M. (1991). Sequence of the gene 
(phe $A$ ) encoding phenol monooxygenase from Pseudomonas sp. EST1001: expression in Escherichia coli and Pseudomonas putida. Gene $102,13-18$.

Oki, T. (1988). Antitumor anthracycline antibiotics from microbial origins. In Anthracycline and Anthracenedione-Based Anticancer Agents, p. 108. Edited by J. W. Lown. Amsterdam: Elsevier.

Otten, S. L., Stutzman-Engwall, K. J. \& Hutchinson, C. R. (1990). Cloning and expression of daunorubicin biosynthesis genes from Streptomyces peucetius and Streptomyces peucetius subsp. caesius. J Bacteriol 172, 3427-3434.

Perkins, E. J., Gordon, M. P., Caceres, O. \& Lurquin, P. F. (1990). Organization and sequence analysis of the 2,4-dichlorophenol hydroxylase and dichlorocatechol oxidative operons of plasmid pJP4. J Bacteriol 172, 2351-2359.

Russel, M. \& Model, P. (1988). Sequence of thioredoxin reductase from Escherichia coli: relationship to other flavoprotein disulfide oxidoreductases. J Biol Chem 263, 9015-9019.

Sambrook, J., Fritsch, E. F. \& Maniatis, T. (1989). Molecular Cloning: a Laboratory Manual, 2nd edn. Cold Spring Harbor, NY: Cold Spring Harbor Laboratory.

Smith, D. B. \& Johnson, K. S. (1988). Single-step purification of polypeptides expressed in Escherichia coli as fusion proteins with glutathione S-transferase. Gene 67, 31-40.

Stassi, D., Donadio, S., Staver, M. J. \& Katz, L. (1993). Identification of a Saccharopolyspora erytbraea gene required for the final hydroxylation step in erythromycin biosynthesis. $J$ Bacteriol 175, 182-189.

Strohl, W. R. (1992). Compilation and analysis of DNA sequences associated with apparent Streptomycetes promoters. Nucleic Acids Res 20, 961-974.

Strohl, W. R., Bartel, P. L., Connors, N. C., Zhu, C.-B., Dosch, D. C., Beale, J. M., Floss, H. G., Stutzman-Engwall, K., Otten, S. L. 8 Hutchinson, C. R. (1989). Biosynthesis of natural and hybrid polyketides by anthracycline-producing Streptomycetes. In Genetics and Molecular Biology of Industrial Microorganisms, pp. 68-84. Edited by C. L. Hershberger, S. W. Queener \& G. Hegeman. Washington, DC: American Society for Microbiology.

Stutzman-Engwall, K. J. \& Hutchinson, C. R. (1989). Multigene families for anthracyclines: antibiotic production in Streptomyces peucetius. Proc Natl Acad Sci US A 86, 3135-3139.

Tabor, S. \& Richardson, C. C. (1985). A bacteriophage T7 RNA polymerase/promoter system for controlled exclusive expression of specific genes. Proc Natl Acad Sci US A 82, 1074-1078.

Vara, J., Lewandowska-Skarbek, M., Wang, Y.-G., Donadio, S. \& Hutchinson, C. R. (1989). Cloning of genes governing the deoxysugar portion of the erythromycin biosynthesis pathway in Saccharopolyspora erythraea (Streptomyces erythreus). J Bacteriol 171, 5872-5881.

Weber, J. M., Leung, J. O., Swanson, S. J., Idler, K. B. \& MCAlpine, J. B. (1991). An erythromycin derivative produced by targeted gene disruption in Saccharopolyspora erythraea. Science 252, 114-116.

Weijer, W. J., Hofsteenge, J., Vereijken, J. M., Jekel, P. A. \& Beintema, J. J. (1982). Primary structure of p-hydroxybenzoate hydroxylase from Pseudomonas fluorescens. Biochim Biophys Acta 704, 385-388.

White, R. J. \& Stroshane, R. M. (1984). Daunorubicin and adriamycin: properties, biosynthesis, and fermentation. In Biotechnology of Industrial Antibiotics, vol. 22, pp. 569-594. Edited by E. J. Vandamme. New York: Marcel Dekker.

Wierenga, R. K., Terpstra, P. \& Hol, W. G. J. (1986). Interaction of pyrophosphate moieties with $\alpha$-helices in dinucleotide binding proteins. J Mol Biol 187, 101-107.

Yanisch-Perron, C., Vieira, J. \& Messing, J. (1985). Improved M13 phage cloning vectors and host strains: nucleotide sequence of the M13mp18 and pUC19 vectors. Gene 33, 103-119.

Received 18 November 1994; accepted 23 December 1994. 